\title{
Educação, (in)justiça social e direitos humanos: combatendo desigualdades na globalização turbocapitalista*
}

\author{
EVA GAMARNIKOW \\ Universidade de Londres \\ Tradução de Jeffrey Hoff \\ Revisão técnica de Antonio \\ Flavio Barbosa Moreira
}

Esta fala tem quatro partes. Começarei abordando a justiça social. Tratarei, em seguida, do atual contexto do capitalismo e do neoliberalismo globais. A terceira parte focalizará as políticas da educacão e, numa quarta seção, argumentarei em favor do discurso de direitos, ao pensar a justiça social e a educação.

\section{JUSTIÇA SOCIAL}

A justiça social é ao mesmo tempo um conceito altamente debatido e muito amplo, que oferece espaço para diferentes reflexões e discussões a respeito de mudanças sociais progressistas. Quero falar dessas questões em ordem inversa.

Por ser um espaço político aberto, a justiça social evoca muitas ideias, esperanças e desafios. Aqui, a justiça social é também profundamente influenciada pelo contexto social e pelas condições históricas da localidade social na qual ela emerge. No Brasil, há um rico histórico de engajamento político por justiça social: o * Conferência proferida por ocasião da 34a Reunião Anual da Associação Nacional de
Pós-Graduação e Pesquisa em Educação (ANPEd). 
Fórum Social Mundial, cujas origens estão em Porto Alegre e cujo lema, "Um outro mundo é possível", segue inspirando ativismos antineoliberais e antiglobalização ao redor do mundo; o Movimento dos Trabalhadores Sem Terra, o MST, lutando por terras e por uma educação democrática; a teologia da libertação, cujo radical e progressista ponto de vista a respeito do papel da religião em sociedades desiguais e não democráticas, a "opção preferencial pelos pobres”, segue influenciando muitos ativistas da justiça social mundo afora; todas as lutas dos povos indígenas que buscam preservar suas culturas e de ambientalistas comprometidos com a preservação das florestas tropicais do Brasil; e, por último, mas não menos importante, Paulo Freire, cuja crítica à passividade da "educação bancária" e a noção de pedagogia crítica encontram adeptos em grande parte dos trabalhos de mestrado e doutorado que meus alunos me apresentam. Assim, me sinto muito honrada por estar aqui, e sei que tenho muito o que aprender com vocês e com a orgulhosa tradição brasileira de engajamento em prol da justiça social.

Enfoco agora abordagens mais acadêmicas do tema da justiça social. Há, nas ciências sociais e nas humanidades, uma longa história de trabalhos conceituais, analíticos e empíricos tratando da justiça social. Não pretendo examiná-los com detalhes, mas apenas simplesmente demarcar algumas das questões gerais e argumentos básicos.

Talvez o ponto-chave para iniciarmos seja a obra de John Rawls, cujo livro A theory of justice ${ }^{1}$ [Uma teoria da justiça] oferece um modo de pensar sobre a justiça social que ainda acredito ser útil. Ele afirma que justiça tem relação com justa distribuição de recursos e oportunidades. $\mathrm{O}$ argumento é longo e detalhado, mas a conclusão, o que é relevante para o nosso propósito, é a de que a desigualdade de distribuição só é justificável se for para beneficiar aqueles que têm dificuldades. O que acho interessante nessa perspectiva é a sua contínua ressonância cultural, ideológica e política. Ela segue inspirando políticas de redistribuição democrática mais igualitárias. Até mesmo neoliberais mais extremos lançam mão dessa definição popular de justiça quando argumentam que as desigualdades produzidas pelos mercados eventualmente melhoram a situação de todos, por meio do efeito "trickle-down", o processo pelo qual os ricos investem e criam empregos, o que supostamente torna os pobres menos pobres.

A ênfase de Rawls na distribuição de recursos - ou seja, na economia - foi criticada por feministas, antirracistas e outros preocupados com as políticas da diferença e da diversidade. Esses grupos argumentam que a injustiça tem também outras dimensões, relacionais. E aqui me refiro a escritoras como Nancy Fraser e Iris Young. Fraser argumenta que a justiça tem duas dimensões: justiça distributiva, aquela que lida com exploração, marginalização e privação no campo econômico; e justiça cultural, que se preocupa com a dominação, o não reconhecimento e o desrespeito culturais. Iris Young, cujo trabalho enfoca a democracia e a participação

1 John Rawls, $A$ theory of justice, Cambridge, Harvard University Press, 2000 (revised edition). 
como elementos-chave para a justiça, fala de cinco "faces da opressão": exploração, marginalização, desempoderamento, imperialismo cultural e violência.

O que é interessante nessas diferentes abordagens da justiça social é que elas voltam a nossa atenção para noções de bem viver e o sentido de ser humano. Há aqui uma sobreposição com os direitos humanos, dos quais falarei adiante.

\section{NEOLIBERALISMO E TURBOCAPITALISMO GLOBAL}

Duas semanas atrás, eu estava em Atenas, na Grécia, num seminário e conferência organizados por um programa de mestrado conjunto entre o Instituto de Educação e a Universidade de Atenas. Enquanto estava lá, as pessoas comentavam os cortes de $10 \%$ em pagamento e pensão, já implementados, e os adicionais cortes de $10 \%$ que estavam por vir no futuro próximo. Pessoas perdiam suas casas, algumas famílias mudavam-se de volta às áreas rurais para tentar sobreviver por meio da agricultura de subsistência e o desemprego entre os jovens avançava rumo à proporção de 50\%. A Grécia está à frente na atual crise econômica e social, sendo seguida dos países identificados com o desrespeitoso acrônimo PIGS [em inglês a sigla forma a palavra "porcos"] - Portugal, Itália, Irlanda e Espanha.

A situação no Brasil, eu sei, é bem diferente. A economia brasileira está em efervescência e, diferente da situação de muitos países europeus onde as desigualdades estão crescendo rapidamente, o Brasil, assim como outros países latino-americanos, tem tido uma pequena redução na desigualdade. Isso, dependendo da fonte, é tido ou como consequência do sucesso de programas de redistribuição antipobreza, ou em razão da expansão dos serviços manufaturados para um mercado doméstico em crescimento, ou por ambos os motivos. Contudo, a redução em desigualdade e pobreza precisa ser contextualizada. O Brasil constumava ser o país mais desigual do mundo: seu coeficiente Gini era 0,61 em 1990, e agora é um "baixo" 0,53. Então, o Brasil é ainda uma sociedade grandemente desigual, com milhões de pessoas vivendo em situação de pobreza (16,3 milhões, de acordo com o último Censo).

Com base em minhas leituras sobre o Brasil, antes de vir para cá, fica também claro que esse grande crescimento econômico dos últimos anos resultou em inflação, altas taxas de juros e um aumento no valor do real. Isso tem atraído investimentos internos e importações, mas dificultado as exportações. A crescente integração do Brasil em relação à economia global causa resultados ambivalentes, com políticas que não tendem a mudar muito, para que sigam atraindo investimento estrangeiro para a Copa do Mundo de 2014 e as Olimpíadas de 2016. O que isso significa é que o milagre das "onças latino-americanas" (meu próprio neologismo, inspirado nos "tigres asiáticos") está incorporado entre os feitos da economia capitalista globalizada.

A crise atual, como foi experienciada na Europa, nos Estados Unidos e em outros países, começou com a crise dos bancos, o resultado da liberalização de capital financeiro nos anos de 1980 que levou àquilo que Hutton chamou de práticas de "banca de cassino". Seguindo o argumento marxista, a necessidade capitalista de acumulação requer constantes adições de novas vias. Nesse estágio avançado, a 
expansão capitalista baseou-se em dívidas. A crise bancária foi, com efeito, causada por excesso de dívidas - as mesmas dívidas que abasteceram o boom econômico das últimas décadas. O Brasil está certamente integrado à economia de dívidas: em Natal (de acordo com uma reportagem do The Guardian), 40\% da renda familiar são dedicados ao pagamento de dívidas e, no país como um todo, uma média de $65 \%$ da renda das famílias é dedicada às dívidas; além disso, os governos dos estados e o Distrito Federal também estão endividados.

A crise capitalista tornou-se uma crise social na Europa e nos Estados Unidos, pois os governos e as instituições internacionais estavam concentrados em salvar os bancos, e assim salvar o capitalismo, por meio da imposição de políticas neoliberais consideravelmente severas.

O neoliberalismo caminha lado a lado com o turbocapitalismo - uma impiedosa e triunfante forma de capitalismo que emergiu com a queda do Muro de Berlim e o descarte do socialismo como alternativa. "Turbocapitalismo" é um conceito desenvolvido por Litwak, um general estadunidense que costumava glorificar os benefícios da globalização no contexto do aparecimento das economias dos tigres asiáticos. Já na minha utilização, o termo "turbocapitalismo" tem uma conotação negativa, para descrever uma sociedade capitalista que está incorporada a uma política e a uma ideologia de TINA ("There Is No Alternative" - Não há alternativa: utilizo o termo cunhado nos anos de 1980 por Margaret Thatcher). Essa representação profundamente fatalista opera de modo que solapa a esperança e a visão; é esse o poder ideológico do turbocapitalismo neoliberal.

O neoliberalismo não é novidade no mundo anglófono, onde há uma longa história em que se conecta o conceito de autonomia individual, tanto radical quanto antifeudal e antiabsolutista, ao capitalismo e à ideia de que a melhor forma de expressar liberdade é por meio dos mercados e do "homem econômico". Assim, a autonomia individual foi transformada em individualismo possessivo. $\mathrm{O}$ papel do Estado nessa distopia é simplesmente o de garantir a ordem social, assim permitindo que a mão invisível do mercado opere. Qualquer outra forma de atuação estatal é vista como uma ilegítima interferência que comprometeria a operação do mercado e o livre-arbítrio individual. Nessa visão do mundo, a pior forma de interferência estatal é a engenharia social do estado de bem-estar social [the welfare state], já que impede que os pobres trabalhem, ao torná-los dependentes das doações do governo. O bem-estar social mina, portanto, ambas as formas de "liberdade" do trabalho; para citar Marx - a liberdade da propriedade que força os trabalhadores a livremente escolher empregos de baixa remuneração.

O neoliberalismo também não é novidade para a América Latina. Há uma longa e difícil história a esse respeito - a derrubada de Allende em 1973 (o 11 de Setembro original, do qual as pessoas costumam esquecer), o Consenso de Washington do Banco Mundial e a miséria causada pelos ajustes estruturais que seguiram o início da "crise da dívida" dos anos de 1970, o North American Free Trade Agreement (NAFTA), e assim por diante. 
Nesta era de turbocapitalismo global neoliberal, a única forma de intervenção estatal entendida como legítima é a que se dá na educação. Examinemos, então, a educação.

\section{EDUCAÇÃO}

Tony Blair era famoso pelo seu mantra "educação, educação, educação" como a solução para indivíduos e sociedades na era da globalização. A ideologia da globalização turbocapitalista é a de que a "educação" é necessária porque a economia da "informação", ou do "conhecimento", necessita de trabalhadores educados. Então, a educação torna-se a solução para o indivíduo - entrar no mercado de trabalho e melhorar suas possibilidades de vida ao garantir que venha a ser empregado na nova economia. Do ponto de vista de países individuais no mundo globalizado, educar os cidadãos é a única estratégia viável para a sobrevivência econômica - competindo com êxito por investimentos e empregos na economia global.

O problema dessa solução da educação como desenvolvimento de capital humano é que se trata de uma solução parcial: funciona, ou parece funcionar, apenas enquanto a economia vai bem. $\mathrm{Na}$ atual crise na Europa, nos Estados Unidos, e no Caribe e América Central, a educação deixa de ser uma forma de garantia. A cruel ironia da crise atual é que agora nós temos as populações mais altamente educadas $e$ não temos empregos.

A crise nos ensina o que eu tenho argumentado por muitos anos.

1. A educação não é $a$ solução. A educação não "gera" ofertas de emprego sob o capitalismo. Ao contrário, as ofertas de emprego são resultado de investimentos capitalistas e decisões sobre quais tipos de emprego serão criados e quais tipos de trabalhadores serão empregados.

2. A educação entra nesse cenário do trabalho como um mecanismo de seleção e filtro, não como garantia de emprego. E quanto mais educação todo mundo tem, menor valor ela tem no mercado. Os salários pagos pela educação decaem à medida que a oferta de trabalhadores educados aumenta (artigo do The Guardian, "Value of university degree falls as number of graduates rises", NB 25 ago. 2011 ["Valor do diploma universitário cai quando o número de graduados sobe”]). A relação educação-emprego na era da educação em massa é uma hierarquia em crescimento entre instituições educacionais e a crescente importância das redes e conexões do capital social, isto é: corrupção e nepotismo. Infelizmente, a educação mantém sua importância para aqueles que não a têm, e que são excluídos por conta disso.

3. A conexão entre educação e mobilidade social é também muito mais complexa e problemática. A mobilidade social não é causada pela educação, mas pelo crescimento e mudança econômica, como está acontecendo no Brasil agora mesmo, e como aconteceu no Reino Unido e nos Estados Unidos nos 
anos de 1950 e 1960. É isso que nós, sociólogos, chamamos de "mobilidade social estrutural". Para que uma mobilidade social disseminada aconteça, é necessário um aumento relativo das ocupações de remuneração mais alta e, concomitantemente, uma diminuição das ocupações de baixa remuneração e baixo status. Mas o importante de se notar aqui é que a mobilidade social se baseia nas desigualdades da estrutura ocupacional, assim como é uma expressão delas (e para além delas). Para que se possa subir numa hierarquia, é preciso que haja uma hierarquia. Assim, uma sociedade na qual se considera a mobilidade social importante é, fundamentalmente, uma sociedade desigual.

Então, talvez a crise atual possa ser usada para causar uma virada nas nossas ideias sobre o que deveria ser a educação. E para isso vamos nos voltar para os direitos humanos, nem que seja pelo fato de que todos os nossos governos concordaram em segui-los e implementá-los e, portanto, podemos exigir que prestem contas quanto a essas questões.

\section{DIREITOS HUMANOS}

A origem dos direitos humanos vem de uma era mais otimista e esperançosa de democracia social pós-guerra. Estou ciente dos perigos que há em se olhar para o passado através de lentes rosadas idealizantes, e não pretendo fazê-lo. Minha intenção é, sim, contrastar aquela era com o atual liberalismo intenso do turbocapitalismo. Os direitos humanos modernos nasceram logo após o holocausto e tornaram-se uma expressão do "nunca mais" por meio da construção de um mito político alternativo - o de que nós, enquanto seres humanos, temos direito à dignidade com igualdade, e que o papel do Estado é promover e proteger essa nossa humanidade igualitária. Esse mito político, que ressoa fortemente com as ideias de justiça social, foi desenvolvido como diretamente oposto ao mito da superioridade racial, este construído como uma solução específica para a crise econômica que assolava a Alemanha nos anos de 1920 . Os direitos humanos também representam, portanto, uma lembrança de que há diversas maneiras de se sair de uma crise, e que racismo, fascismo e ditaduras são tão plausíveis e possíveis quanto formas mais progressistas de política, como todos sabemos.

Voltando-me para o direito à educação, meu argumento aqui é de que, como educadores que trabalham na atual era turbocapitalista neoliberal, deveríamos resgatar o artigo 29 da Convenção sobre os Direitos da Criança da Organização das Nações Unidas (ONU), ratificada por todos os países do mundo, exceto pelos Estados Unidos e pela Somália. Essa convenção apresenta dois artigos relacionados à educação. $\mathrm{O}$ artigo 28 é sobre as escolas e os sistemas educacionais.

\section{ARTIGO 28}

Os Estados Partes reconhecem o direito da criança à educação, e com a visão de alcançar progressivamente esse direito, que é baseado na igualdade de oportunidade, eles devem, particularmente: 
a Tornar a educação primária obrigatória, acessível e gratuita para todos;

b| Estimular o desenvolvimento de diferentes formas de educação secundária, incluindo educação geral e profissional; torná-las disponíveis e acessíveis [...] e tomar medidas apropriadas, tais como a introdução da educação gratuita e $[\ldots]$ auxílio financeiro;

c| Tornar a educação superior acessível para todos no âmbito da capacidade de cada um;

d) Tornar informações e orientações educacionais e vocacionais disponíveis e acessíveis para todas as crianças;

e Tomar medidas que encorajem a frequência às escolas e reduzam os níveis de evasão.

Do ponto de vista da sociologia da educação, há uma série de tensões presentes no artigo 28:

1. Ele pressupõe que igualdade de oportunidade seja algo possível em uma sociedade desigual;

2. Trata como não problemáticas as diferentes formas de escolas secundárias, isto é, acadêmicas e profissionais, que na verdade resultam em oportunidades desiguais;

3. Pressupõe a existência de uma capacidade ou inteligência inata/biológica.

O artigo 28, apoiado pelo Education for All (EFA) e pelas Millennium Development Goals (MDGs), está preocupado em garantir que todas as crianças tenham acesso a escolas e a um sistema educacional. Isso é importante, especialmente num contexto em que, mundo afora, 75 milhões de crianças não vão à escola e 776 milhões de adultos não têm um nível básico de alfabetização. A questão encontra uma ressonância especial no caso do Brasil, onde há desigualdades educacionais enormes no que diz respeito ao acesso a escolas e ensino superior, e à qualidade da educação e níveis de evasão. Mas o artigo 28 ignora o papel das escolas e dos sistemas educacionais enquanto reprodutores da desigualdade social, ao produzirem distinções educacionais e desigualdades. É politicamente interessante, no contexto do TINA, que as evidências dos estudos do Programme for International Student Assessment (PISA) mostrem que sociedades mais igualitárias com sistemas educacionais mais igualitários têm os melhores níveis de sucesso na realização educacional. Esse tipo de evidência, entretanto, é ignorado e silenciado no nível das políticas internacionais para a educação. Indo contra as evidências, os modelos da Organisation for Economic Co-operation and Development (OECD) do Banco Mundial para uma reforma sistêmica da educação recomendam e proporcionam financiamento para estratégias neoliberais, tais como: descentralização, mercantilização e privatização, todas medidas que acentuam as desigualdades na educação.

$\mathrm{O}$ artigo 28 não pode, portanto, bastar-se em si mesmo, isoladamente. Meu argumento aqui é de que deveríamos voltar as atenções para o artigo 29, que se preocupa com as metas e valores da educação. 


\section{ARTIGO 29}

A educação da criança deve ser direcionada para:

a O desenvolvimento da personalidade, dos talentos e das habilidades mentais e físicas da criança ao seu potencial máximo;

b| O desenvolvimento do respeito pelos direitos humanos e às liberdades fundamentais, e para os princípios resguardados na Carta da ONU;

c| O desenvolvimento do respeito pelos pais da criança, sua identidade cultural, linguagem e valores, pelos valores nacionais do país em que a criança vive, ou do país do qual ela vem, e por civilizações diferentes da sua própria;

d) O preparo da criança para a vida responsável em uma sociedade livre, num espírito de compreensão, paz, tolerância, igualdade entre os sexos, e amizade entre os povos, grupos étnicos, nacionais e religiosos e pessoas de origem indígena;

e $\mathrm{O}$ desenvolvimento do respeito ao meio ambiente.

Esse artigo, diferentemente do artigo 28, deixa de lado a relação entre educação e trabalho e vai além dela. Promove uma visão mais esperançosa e otimista daquilo que a educação pode/deve/precisa legalmente ser: o local do aprendizado sobre justiça social e o que significa um ser humano, que é o sujeito dos direitos humanos. $\mathrm{O}$ artigo 29 é sobre a educação em direitos humanos. Ele pode não ser perfeito como currículo, mas as metas e valores dos quais ele está imbuído são diametralmente opostos àqueles presentes nas soluções impostas pelo turbocapitalismo global neoliberal. Como professores, nós temos o dever de ensinar a respeito dos direitos humanos, e as pessoas que ensinamos têm direito a essa educação. $\mathrm{O}$ artigo 29 nos mostra que existe alternativa - Uma outra sociedade é possível!

\section{SOBRE A AUTORA}

Eva Gamarnikow é $\mathrm{PhD}$ em sociologia pela Universidade de Londres. Professora da mesma instituição.

E-mail: e.gamarnikow@ioe.ac.uk

Recebido em novembro de 2011 Aprovado em novembro de 2011 


\section{EVA GAMARNIKOW}

Educação, (in)justiça social e direitos humanos: combatendo desigualdades na globalização turbocapitalista

Iniciando com considerações sobre justiça e seus vínculos com o contexto social e as políticas de distribuição de recursos e oportunidades, em seguida, o artigo analisa o atual contexto do capitalismo e do neoliberalismo, destacando a crise global, o dinamismo da economia brasileira e seus resultados ambíguos para o país, em particular, no que se refere ao combate às desigualdades sociais. Trata principalmente do lugar da educação no contexto econômico, argumentando em favor do discurso de direitos ao pensar possibilidades de mudança.

Palavras-chave: educação; justiça social; direitos humanos.

Education, social (in)justice and human rights: tackling inequalities in turbo-capitalist globalization

This article starts with considerations on justice and its links with the social context and policies of distribution of resources and opportunities. Then it analyzes the current context of capitalism and neoliberalism, highlighting the global crisis, the dynamism of the Brazilian economy and its ambiguous results for the country, particularly with regard to tackling social inequalities. It discusses in particular the place of education in the economic context, arguing for the rights discourse by thinking about possibilities of change.

Keywords: education; social justice; buman rights.

Educación, (in)justicia social y derechos humanos: combatiendo desigualdades en la globalización turbo-capitalista

Empezando con consideraciones sobre justicia y sus vinculos con el contexto social y las politicas de distribución de recursos y oportunidades, el texto analiza el actual contexto del capitalismo y del neoliberalismo, destacando la crisis global, el dinamismo de la economía brasileña y sus resultados ambiguos para el país, particularmente en lo que se refiere al combate a las desigualdades sociales. Trata, particularmente, del lugar de la educación en el contexto económico, argumentando en favor del discurso de derechos al pensar posibilidades de cambio.

Palabras clave: educación; justicia social; derechos humanos. 